\title{
Effect of task length on remembered and predicted duration
}

\author{
MiCHAEL M. RoY \\ Elizabethtown College, Elizabethtown, Pennsylvania \\ AND \\ Nicholas J. S. Christenfeld \\ University of California, San Diego, California
}

\begin{abstract}
Vierordt's (1868) law states that when estimating the duration of a previous task, people overestimate short durations and underestimate long ones. We examine whether this same pattern holds for remembered and predicted duration for tasks lasting between 1 and $15 \mathrm{~min}$. In support of Vierordt's law and its extension to future duration estimates, task duration tended to be overestimated for short tasks (less than $2 \mathrm{~min}$ ) and underestimated for long tasks for both remembered and predicted duration.
\end{abstract}

Researchers have noted that task duration can affect both the size and direction of error in remembered duration. Vierordt's law (1868) states that in retrospect, shorter durations tend to be overestimated, whereas longer durations tend to be underestimated, and reviews of empirical work on estimation of previous task duration support this law (Block \& Zakay, 1997; Fraisse, 1963; Poynter, 1989; Wallace \& Rabin, 1960). Much of this work is based on tasks that lasted no more than a few seconds. Yarmey (2000) examined whether Vierordt's law held when the frame of reference for the events being estimated was minutes instead of seconds and fractions of a second; participants made retrospective estimation for eventssuch as washing a load of laundry or walking a specific distance - in a natural setting. In support of Vierordt's law, participants overestimated the shorter tasks and underestimated the longer ones. Results indicated a possible cutoff point between what is considered short and long-and, therefore, between overestimation and underestimationof 2-10 min, depending on the task.

There is reason, both empirically and theoretically, to suspect that Vierordt's law might also apply to predictions of future task duration. Previous research has found that participants predicting duration for tasks lasting less than 5 min tended to overestimate the duration (Burt \& Kemp, 1994; Thomas, Handley, \& Newstead, 2004; Thomas, Newstead, \& Handley, 2003), whereas participants predicting duration for tasks lasting longer than $5 \mathrm{~min}$ - with some taking days or even weeks to complete-underestimated the duration (Buehler \& Griffin, 2003; Buehler, Griffin, \& MacDonald, 1997; Buehler, Griffin, \& Ross, 1994; Buehler, Messervey, \& Griffin, 2005; Byram, 1997; Connolly \& Dean, 1997; Francis-Smythe \& Robertson, 1999; Grif- fin \& Buehler, 1999; Jorgensen \& Sjoberg, 2001; Josephs \& Hahn, 1995; Koneçni \& Ebbesen, 1976; König, 2005; Koole \& Van't Spijker, 2000; Kruger \& Evans, 2004; Molokken-Ostvold \& Jorgensen, 2005; Newby-Clark, Ross, Buehler, Koehler, \& Griffin, 2000; Taylor, Pham, Rivkin, \& Armor, 1998). The tendency for overestimation found in experiments that used short duration tasks, and for underestimation in experiments that used long duration tasks, might rest on exactly the same foundation as the bias in remembered duration. That is, when predicting how long a task will take, people may consult their memories of past completion times; thus, any bias in memory will simply transfer to prediction (Roy, Christenfeld, \& McKenzie, 2005). For example, task novelty has a similar effect on bias for both remembered and predicted duration, with novel tasks likely overestimated and familiar tasks likely underestimated (Roy \& Christenfeld, 2007). In contrast, previous explanations for bias in predicted duration - such as the planning fallacy (Kahneman \& Tversky, 1982) — claim that bias likely occurs because of people's disregarding prior experience and focusing narrowly on the specific demands of the task at hand when estimating completion time.

Although a similar pattern of overestimation for short tasks and underestimation for long tasks has been found for both memory and prediction, the studies showing overestimation, underestimation, memory effects, and prediction effects differ in too many other ways to allow direct comparison or confident conclusions. To explore this question directly, an experiment is needed that varies the length of a given task and examines the impact on estimations of both past and future duration. In the present article, we present data from such an experiment, in which a single task

M. M. Roy, roym@etown.edu 
was varied in duration to ensure that differences found in estimation were due to duration of the task and not to the idiosyncrasies of particular tasks. Participants performed a paper-counting task of varying length and estimated duration either before or after completing the task. We chose a paper-counting task because it allowed us to keep the underlying task constant but vary duration by simply changing the number of sheets that the participant had to count. Doing so allows comparison of both the direction of any bias, overestimation or underestimation, and the size of that bias for both memory and prediction.

\section{METHOD}

\section{Participants}

A total of 207 University of California, San Diego students (151 females, 56 males) participated. Participants completed three unrelated experiments, the present experiment being the first of the three. They received course credit for their psychology classes in exchange for participation.

\section{Design}

Duration of the task and perspective of estimation were manipulated entirely between subjects. Participants in the prediction condition were asked to estimate how long it would take to count a stack of $50(n=28), 100(n=26), 250(n=26)$, or $500(n=20)$ sheets of paper, whereas participants in the memory condition were asked to estimate how long it had just taken to count a stack of $50(n=31)$, $100(n=34), 250(n=22)$, or $500(n=20)$ sheets of paper. Each participant made a single estimation.

\section{Procedure}

Participants arrived singly for the experiment and were asked to remove their watches and any rings or bracelets that they were wearing. They were told that this was because they would be working with their hands on the task, although it actually served to ensure that they could not consult their watches and calculate how long the task was taking. There was also no clock in the room. A stack of approximately 700 sheets of paper was placed in front of the participant, and he or she was asked to count out - depending on the condition-50, 100,250 , or 500 sheets of paper by placing them in perpendicular stacks of 10 sheets.

In the prediction condition, participants were asked to estimate before they performed the task how long (in minutes and seconds) it would take them to count out the sheets. In the memory condition, participants were asked to count out the specified number of sheets and were then asked to estimate how long it had taken. The experimenter surreptitiously timed the actual duration for all participants.

\section{Dependent Measure}

An index was created by taking the log of the ratio of estimated duration to actual duration in order to assess accuracy of estimates (Roy \& Christenfeld, 2007). This index, which we refer to as $\log$ proportional error, has a number of benefits. It simplifies interpretation of the results: A negative score indicates underestimation, a score of zero indicates perfect accuracy, and a positive score indicates overestimation. By converting to proportional bias, differences between estimated and actual duration for tasks of varying duration can be directly compared. Finally, taking the log of the proportional error normalized the data; estimates of duration - and to a lesser extent, actual task durations - were positively skewed. Skewness can be exacerbated by using a ratio of estimated duration to actual duration, because underestimation would be represented by values that are between 0 and 1 , and overestimation would be represented by values that are larger than 1 and unbounded. Taking the log of the ratio removes skew and makes both underestimation and overestimation unbounded.

\section{RESULTS}

The median duration to count $50,100,250$, and 500 sheets of paper was $1.25,2.64,6.24$, and $15.08 \mathrm{~min}$ in the memory condition, and $.99,2.18,6.73$, and $17.0 \mathrm{~min}$ in the prediction condition, respectively. A $4 \times 2$ ANOVA of the log of the actual duration revealed the expected difference in duration due to number of sheets counted $[F(3,199)=696.2, p<$ $\left..001, \eta^{2}=.9\right]$ and a significant interaction between number of sheets counted and perspective of estimation, memory, or prediction $\left[F(3,199)=3.99, p=.009, \eta^{2}=.005\right]$. There was a tendency for participants in the prediction condition to perform the task more quickly when counting 50 and 100 sheets and more slowly when counting 250 and 500 sheets (see Figure 1).

We examined the effect of task duration (measured by the log of the actual duration [ActD]) on bias (measured by log proportional error [LPE]) for both remembered and predicted duration. By using linear regression to examine bias, we were able to take advantage of between-task differences as well as individual, within-task differences in time to complete the task. Bias in remembered duration was predicted by the formula $\mathrm{LPE}=-.125(\mathrm{ActD})+$ $.036\left[F(106)=6.06, p=.015, R^{2}=.06\right]$ (see Figure 2). Bias in estimated future task duration was predicted by the formula LPE $=-.185(\mathrm{ActD})+.034[F(99)=12.04$, $\left.p<.001, R^{2}=.11\right]$ (see Figure 3). The regression equations for bias in both remembered and predicted durations are characterized by a negative slope and a positive intercept, indicating that short durations tended to be overestimated, but that as task duration increased, the tendency to underestimate became more pronounced. Although the slopes of both regression equations were significant, the intercepts were not significantly different from zero ( $p$ s $>$.3). Participants tended to overestimate short durations, but the bias was not significant. The crossover point between overestimation and underestimation was at $1 \mathrm{~min}$ $56 \mathrm{sec}$ for the memory condition and at $1 \mathrm{~min} 32 \mathrm{sec}$ for

\section{Effect of Condition on Task Performance}

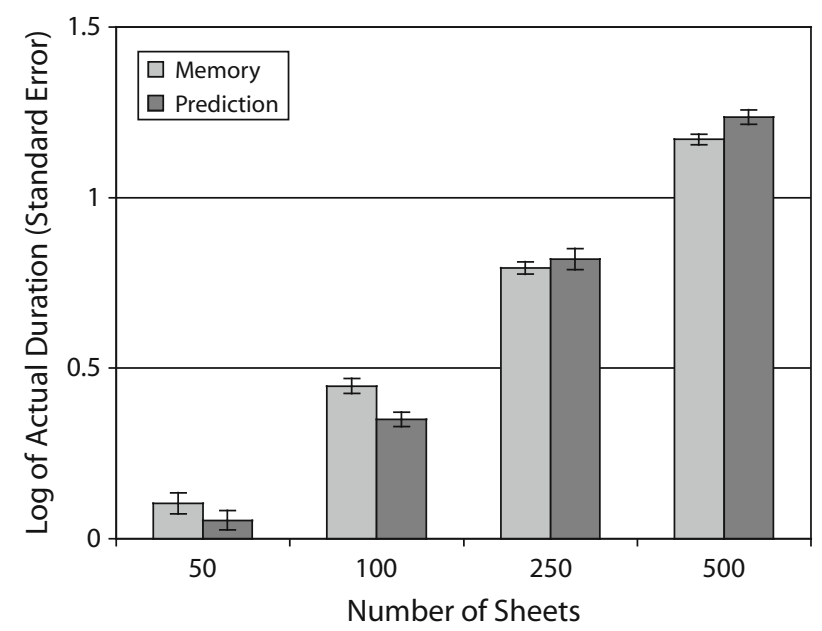

Figure 1. Effect of condition-memory or prediction-on the duration to complete the task. 


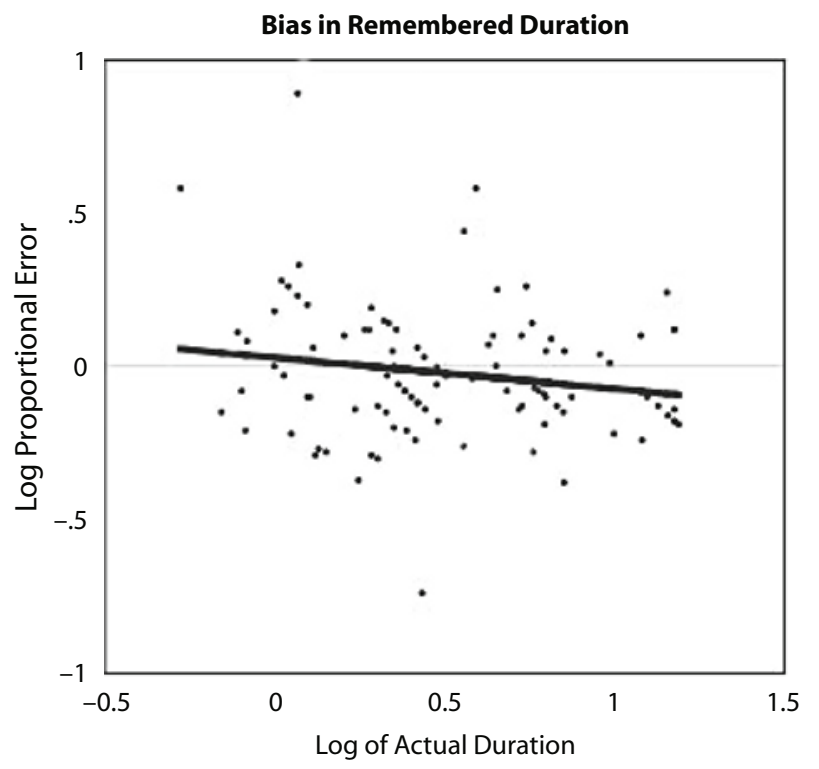

Figure 2. Log proportional error (log of estimated duration/ actual duration) for remembered duration as a function of $\log$ of actual task duration. Each point corresponds to an individual participant. Positive values indicate overestimation, and negative values indicate underestimation.

the prediction condition. Although the slope was steeper for predicted duration than remembered duration $(-.185$ vs. -.125$)$, this difference was not significant $[t(201)=$ $1.15, p>$.2]. The scatterplots reveal more dispersion of error scores for the prediction condition; however, the difference in the magnitude of the correlations between actual duration and log proportional error for memory and prediction was not significant $[t(201)=.75, p>.4]$.

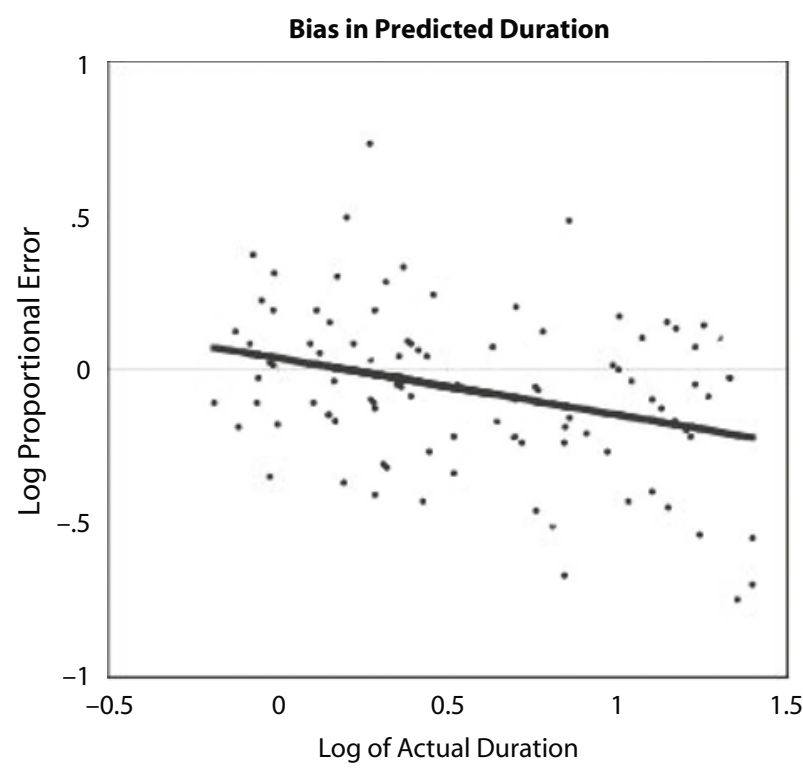

Figure 3. Log proportional error (log of estimated duration/ actual duration) for predicted duration as a function of $\log$ of actual task duration.
Accuracy in estimation can be measured not only by looking at average bias, but also by examining the correlation between estimated behavior and actual behavior, which provides a measure of what is sometimes called discrimination accuracy (Epley \& Dunning, 2006). Overall, participants were well calibrated in the relative durations of the different tasks: The correlation between log estimated duration and $\log$ actual duration was .86 for all participants in the memory condition and .84 for all participants in the prediction condition. Individual participants were also fairly well calibrated about whether they were slow or fast within each condition. When correlations were computed between log estimated and log actual duration for participants within each of the eight conditions, the average correlation was .38 for remembered duration and .48 for predicted duration.

Overall, participants overestimated the duration to count 50 sheets by $5.9 \%$ and underestimated the duration to count 100,250 , and 500 sheets by $17.8 \%, 24.5 \%$, and $36.2 \%$, respectively.

\section{DISCUSSION}

The results do provide support for Vierordt's law (1868) when using tasks with minutes instead of seconds as a frame of reference. Task duration had a significant effect on magnitude of bias: Participants were inclined to overestimate when the task was short and to underestimate when the task was longer, with the amount of underestimation escalating as task duration increased. For the paper-counting task, the cutoff between short and long was between 1.5 and $2 \mathrm{~min}$. The results indicate that Vierordt's law applies not just to recollections of past tasks, but also to estimates of future task duration. We found no difference between past and future estimation, with both affected in the same manner by duration of the task.

Although this experiment shows that there is a difference between short and long tasks in estimation, it is unlikely that there is a single simple cutoff point that can be applied across all tasks, with different task types producing different cutoff placements (Yarmey, 2000). The frame of reference may also be important, since a task that takes a few hours is considered long when compared with tasks that require only a few minutes, but considered short when compared with ones that occupy several days. As was discussed, it appears that there are separate cutoff points when the frame of reference is seconds and when it is minutes. It is possible that there might also be different cutoff points when the scale is in terms of hours, days, weeks, months, or years. Indeed, consistent with this idea, participants estimating how long ago an event took place overestimated when the task was less than 8 weeks prior, but underestimated when the event took place more than 8 weeks previously (Thompson, Skowronski, \& Lee, 1988).

The difference in the time that participants took to complete the task between the two estimation conditions is somewhat intriguing. Although it may be that the act of making a prediction can be a form of goal setting resulting in a change in behavior (Locke \& Latham, 1990), it is not clear why making a prediction would cause partici- 
pants in the 50- and 100-sheets conditions to be quicker and participants in the 250- and 500-sheets conditions to be slower. These results, however, should be interpreted with some caution, since the effect size for this interaction $\left(\eta^{2}=.005\right)$ was very small (Cohen, 1988).

\section{Possible Causes of Bias for Remembered Duration}

When predicting how long it will take to count a large stack of paper, participants may be overly optimistic, hope that the task will not take very long, and therefore underestimate. Such optimism cannot, however, explain why people should show the same bias after having completed the task. Furthermore, the fact that people also underestimate past duration for the longer tasks is somewhat remarkable, given the particular activity we used. It would be charitable for one to describe the task of counting a large stack of paper as dull. One might predict that a boring task - such as this one-would make time seem to move slowly and thus lead to the overestimation of duration (James, 1890). Furthermore, one might expect the boredom - and thus the extent of overestimation - to grow with the duration of the task. The tendency instead to underestimate past duration appears to be powerful enough for longer tasks that even a dull, repetitive task will be seen as having taken less time than it actually did.

A number of possible explanations have been offered that can account for the findings that increasing task duration can cause retrospective estimates to move from overestimation to underestimation. It could be that the amount of information that a task contains or the number of changes in the task is not commensurate with the duration of the task. Short tasks may have proportionately more information per unit of time than long tasks and are therefore overestimated, whereas long tasks are underestimated (Block \& Reed, 1978; Ornstein, 1969). Although this may generally be so, for the task we used, the amount of information in relation to task duration was fairly constant. It may also be that short tasks require more focused attention than do long tasks, and this added attention to the task might take away from temporal attention, thus causing differences in estimation (Thomas \& Weaver, 1975). Again, given the present task, it is not clear that attention would vary due to task duration, given that all conditions involved the same paper-counting task.

An additional possible explanation for the tendency to underestimate is that there are certain numbers to which participants are likely to round when estimating duration, and the difference between these numbers grows larger with longer duration. This will have two results. First, because there will be an asymmetry in rounding, there will be a tendency toward underestimation (Huttenlocher, Hedges, $\&$ Bradburn, 1990). For example, people may be likely to round to even values for durations less than $10 \mathrm{~min}$ and to multiples of five for durations greater than $10 \mathrm{~min}$. In this case, durations between 9 and 12.5 min will be rounded to $10 \mathrm{~min}$, which is likely to underestimate the average duration of intervals in that range. Second, the extent of that underestimation - in absolute terms - will grow with the duration, as the units of rounding grow. Results from our experiment do indicate that participants were likely to round to certain values, with $75 \%$ of participants rounding to whole values (minutes). In fact, all durations of $7 \mathrm{~min}$ or longer were rounded to integers. Although a rounding explanation can apply to some results, it cannot deal with all of them. Some studies of bias-including Vierordt's (1868) original work, for example - have not asked for explicit estimates, but instead have had participants reproduce durations, and such studies have produced comparable results. Furthermore, although rounding explanations do predict growing absolute error with increased duration, they have more difficulty with increases in proportional error, as was observed in our studies.

Researchers have suggested that there might be differences in internal clocks that mediate short duration and long duration, with the possibility of one running fast and the other running slow. Studies with participants in extended isolation found that estimation of durations of 5 and $10 \mathrm{sec}$ was linked to the participant's body temperature, whereas estimation of duration of $1 \mathrm{~h}$ or more was linked with the participant's sleep-wake cycle (Aschoff, 1984, 1998). More research would be needed to determine whether different bodily states mediate differences in bias for tasks lasting approximately $1 \mathrm{~min}$ and those lasting approximately $10 \mathrm{~min}$. The ability to explain the results from the point of view of a number of different theories is further complicated by the fact that the results could be due to an interaction of a number of these principles, because method of estimation may change with type of task (Jones \& Boltz, 1989).

\section{The Relationship Between Memory and Prediction}

It need not be the case that one would find a similar pattern of overestimation and underestimation for predictions of duration, as has been found for memories of duration. One possible explanation - the memory bias account (Roy, Christenfeld, \& McKenzie, 2005) — holds that bias in prediction is caused by bias in memory. The amount of time that people recall a task having taken is affected by task duration; therefore, when such memories are consulted in making predictions of future duration, a similar bias emerges. Short tasks are remembered as taking longer than they actually did, which in turn will cause overestimations of how long a short task will require in the future. Consistent with this idea, researchers have found that there is a similar effect of experience with a task on both remembered and predicted duration (Roy \& Christenfeld, 2007) and that previous experience affects prediction for how long a task will take (Thomas, Handley, \& Newstead, 2007). Further, it is not even clear how people could make a prediction of duration that is even moderately accurate without some reference to memories of how long similar tasks have taken in the past. As can be seen from the high correlation between predicted and actual duration, people are relatively aware of how long these tasks should take, indicating that they are likely calling on memory in some form while making their predictions. It does not appear likely that bias in prediction is caused by participants' disregarding memory for these tasks. What is still not clear- 
as the previous discussion indicates - is why memory for past task duration is biased.

Although it appears that bias in memory likely causes bias in prediction, it is at least possible that memory of duration and prediction of duration are separate processes that are - just coincidentally — affected similarly by task duration. Previous psychophysical experiments with participants estimating the number of elements in a display found a tendency to overestimate small and underestimate large numbers of stimuli (Treisman, 1985). Researchers have suggested that this regression toward an average number could explain the similar pattern of bias found in remembered duration (Fraisse, 1963). This effect may also cause participants' predictions to be overestimates for short durations and underestimates for long durations. However, there are some differences between the psychophysical experiments and the present experiment that may need to be reconciled. In the psychophysical experiments, repeated quantity judgments were made for stimuli that had defined upper and lower bounds. Distortion toward the center happened closer to these boundaries. Although there is a clear lower bound in the present experiment, there is no clear upper bound. It is possible that the participants may have set their own artificial upper bound for how long the task might take (Huttenlocher et al., 1990); however, given that the manipulation was between subjects with participants making only one duration estimation, it would seem unlikely that all of the participants would construct a similar upper bound for these tasks.

\section{Conclusion}

Vierordt's law (1868) states that task duration affects magnitude and direction of bias in remembered duration. The present study found that bias in both predicted and remembered duration is a function of task duration for tasks that have a frame of reference in minutes. Given the importance of being able to accurately predict how long it will take to complete various tasks - from making a sandwich for your child to completing a manuscript for publication - the extension of Vierordt's law to expected duration is far from trivial. If one is able to determine how and when predicted duration is likely to be biased, then adjustments can be made to improve accuracy.

\section{AUTHOR NOTE}

Part of this work was supported by NIMH National Research Service Award MH14257 to the University of Illinois. A portion of this work was completed while the first author was a postdoctoral trainee in the Quantitative Methods program of the Department of Psychology, University of Illinois at Urbana-Champaign. Correspondence concerning this article should be addressed to M. M. Roy, Department of Psychology, Elizabethtown College, One Alpha Drive, Elizabethtown, PA 17022 (e-mail: roym@etown.edu).

\section{REFERENCES}

Aschoff, J. (1984). Circadian timing. In J. Gibbon \& L. G. Allan (Eds.), Timing and time perception (Annals of the New York Academy of Sciences, Vol. 423, pp. 442-468). New York: New York Academy of Sciences.

AscHOFF, J. (1998). Human perception of short and long time intervals:
Its correlation with body temperature and the duration of wake time. Journal of Biological Rhythms, 13, 437-422.

Block, R. A., \& REED, M. A. (1978). Remembered duration: Evidence for a contextual change hypothesis. Journal of Experimental Psychology: Human Learning \& Memory, 4, 656-665.

Block, R. A., \& ZaKaY, D. (1997). Prospective and retrospective duration judgments: A meta-analytic review. Psychonomic Bulletin \& Review, 4, 184-197.

Buehler, R., \& Griffin, D. (2003). Planning, personality, and prediction: The role of future focus in optimistic time predictions. Organizational Behavior \& Human Decision Processes, 92, 80-90.

Buehler, R., Griffin, D., \& MacDonald, H. (1997). The role of motivated reasoning in optimistic time predictions. Personality \& Social Psychology Bulletin, 23, 238-247.

Buehler, R., Griffin, D., \& Ross, M. (1994). Exploring the "planning fallacy": Why people underestimate their task completion times. Journal of Personality \& Social Psychology, 67, 366-381.

Buehler, R., Messervey, D., \& Griffin, D. (2005). Collaborative planning and prediction: Does group discussion affect optimistic biases in time estimation? Organizational Behavior \& Human Decision Processes, 97, 47-63

Burt, C. D. B., \& KemP, S. (1994). Construction of activity duration and time management potential. Applied Cognitive Psychology, 8, 155-168.

Byram, S. J. (1997). Cognitive and motivational factors influencing time prediction. Journal of Experimental Psychology: Applied, 3, 216-239.

COHEN, J. (1988). Statistical power analysis for the behavioral sciences (2nd ed.) Hillsdale, NJ: Erlbaum.

Connolly, T., \& Dean, D. (1997). Decomposed versus holistic estimates of effort required for software writing tasks. Management Science, 43, 1029-1045.

EPLEY, N., \& DunNING, D. (2006). The mixed blessing of self-knowledge in behavioral prediction: Enhanced discrimination but exacerbated bias. Personality \& Social Psychology Bulletin, 32, 641-655.

Fraisse, P. (1963). The psychology of time. New York: Harper \& Row.

Francis-Smythe, J. A., \& RoberTson, I. T. (1999). On the relationship between time management and time estimation. British Journal of Psychology, 90, 333-347.

GRIFFIN, D., \& BUEHLER, R. (1999). Frequency, probability, and prediction: Easy solutions to cognitive illusions? Cognitive Psychology, $\mathbf{3 8}$, 48-78.

Huttenlocher, J., Hedges, L. V., \& Bradburn, N. M. (1990). Reporting of elapsed time: Bounding and rounding processes in estimation. Journal of Experimental Psychology: Learning, Memory, \& Cognition, 16, 196-213.

JAMES, W. (1890). The principles of psychology. New York: Holt.

Jones, M. R., \& BoltZ, M. (1989). Dynamic attending and responses to time. Psychological Review, 96, 459-491.

Jorgensen, M., \& SJoberG, D. I. K. (2001). Impact of effort estimates on software project work. Information \& Software Technology, 43, 939-948.

JosePhs, R. A., \& Hahn, E. D. (1995). Bias and accuracy in estimation of task duration. Organizational Behavior \& Human Decision Processes, 61, 202-213.

Kahneman, D., \& TVersky, A. (1982). Intuitive prediction: Biases and corrective procedures. In D. Kahneman, P. Slovic, \& A. Tversky (Eds.), Judgment under uncertainty: Heuristics and biases (pp. 414-421). Cambridge: Cambridge University Press.

Koneçni, V. J., \& Ebbesen, E. E. (1976). Distortions of estimates of numerousness and waiting time. Journal of Social Psychology, 100, 45-50.

KöNIG, C. J. (2005). Anchors distort estimates of expected duration. Psychological Reports, 96, 253-256.

KoOLE, S., \& VAN'T SPIJKER, M. (2000). Overcoming the planning fallacy through willpower: Effects of implementation intentions on actual and predicted task-completion times. European Journal of Social Psychology, 30, 873-888.

Kruger, J., \& Evans, M. (2004). If you don't want to be late, enumerate: Unpacking reduces the planning fallacy. Journal of Experimental Social Psychology, 40, 586-598.

Locke, E. A., \& LATHAM, G. P. (1990) A theory of goal setting and task performance. Englewood Cliffs, NJ: Prentice Hall. 
Moloknen-Ostvold, K., \& Jorgensen, M. (2005). Expert estimation of web-development projects: Are software professionals in technical roles more optimistic than those in non-technical roles? Empirical Software Engineering, 10, 7-29.

Newby-Clark, I. R., Ross, M., Buehler, R., Koehler, D. J., \& GrifFIN, D. (2000). People focus on optimistic scenarios and disregard pessimistic scenarios while predicting task completion times. Journal of Experimental Psychology: Applied, 6, 171-182.

ORNSTEIN, R. E. (1969). On the experience of time. Harmondsworth, U.K.: Penguin.

POYNTER, D. (1989). Judging the duration of time intervals: A process of remembering segments of experience. In I. Levin \& D. Zakay (Eds.), Time and human cognition: A life-span perspective (pp. 305-322). Amsterdam: North-Holland.

Roy, M. M., \& Christenfeld, N. J. S. (2007). Bias in memory predicts bias in estimation of future task duration. Memory \& Cognition, 35, 557-564.

Roy, M. M., Christenfeld, N. J. S., \& McKenzie, C. R. M. (2005). Underestimation of future duration: Memory incorrectly used or memory bias. Psychological Bulletin, 131, 738-756.

Taylor, S. E., Pham, L. B., Rivkin, I. D., \& Armor, D. A. (1998). Harnessing the imagination. American Psychologist, 53, 429-439.

Thomas, E. A. C., \& Weaver, W. B. (1975). Cognitive processing and time perception. Perception \& Psychophysics, 17, 363-367.

Thomas, K. E., Handley, S. J., \& Newstead, S. E. (2004). The effect of prior experience on estimating the duration of simple tasks. Current Psychology of Cognition, 22, 83-100.

Thomas, K. E., Handley, S. J., \& Newstead, S. E. (2007). The role of prior task experience in temporal misestimating. Quarterly Journal of Experimental Psychology, 60, 230-240.

Thomas, K. E., Newstead, S. E., \& Handley, S. J. (2003). Exploring the time prediction process: The effect of task experience and complexity on prediction accuracy. Applied Cognitive Psychology, 17, 655-673.

Thompson, C. P., Skowronski, J. J., \& LeE, D. J. (1988). Telescoping in dating naturally occurring events. Memory \& Cognition, 16, 461-468.

Treisman, M. (1985). The magical number seven and some other features of category scaling: Properties of a model for absolute judgment. Journal of Mathematical Psychology, 29, 175-230.

VIERORDT, K. VON (1868). Der Zeitsinn nach Versuchen [The sense of time according to research]. Tübingen: H. Laupp.

Wallace, M., \& Rabin, A. I. (1960). Temporal experience. Psychological Bulletin, 57, 213-236.

YARMEY, A. D. (2000). Retrospective duration estimations for variant and invariant events in field situations. Applied Cognitive Psychology, 14, 45-57.

(Manuscript received August 8, 2006;

revision accepted for publication June 8,2007 .) 